\title{
Comparison of two cotside methods for the detection of hypoglycaemia among neonates in Nepal
}

\author{
M Ellis, D S Manandhar, N Manandhar, J M Land, N Patel, A M de L Costello
}

\begin{abstract}
Aims-To compare two cotside methods of blood glucose measurement (HemoCue and Reflolux II) against a standard laboratory method for the detection of neonatal hypoglycaemia in a developing country maternity hospital where hypoglycaemia is common.
\end{abstract}

Methods -94 newborn infants and 75 of their mothers had blood glucose assessed on the same venous sample using three different methods in the Special Care Baby Unit and postnatal wards, Prasuti Griha Maternity Hospital, Kathmandu, Nepal: HemoCue and Reflolux II at the cotside; Roche Ultimate glucose oxidase method (GOM) in the laboratory.

Results-The mean (SD) values for blood glucose in newborn infants were GOM 2.5 (1.1) mmol/1; Reflolux II 2.1 (0.9); and HemoCue 4.2 (1.2). For mothers the values were GOM 5.3 (1.2) $\mathrm{mmol} / 1$; $\mathrm{Re}$ flolux II 3.6 (1.2); and HemoCue 5.6 (1.0). Bland-Altman plots showed that Reflolux II consistently underreads GOM blood glucose in neonates by $0.5 \mathrm{mmol} / \mathrm{l}$ (SD 0.7) and that HemoCue overreads glucose by $1.7 \mathrm{mmol} / \mathrm{l}$ (SD 0.8). For the detection of hypoglycaemia ( $<2.0 \mathrm{mmol} /$ ), Reflolux II achieved a sensitivity of $83 \%$, a specificity of $62 \%$, and a likelihood ratio of 2.2 . HemoCue produced a sensitivity of $0 \%$ and a specificity of $100 \%$ using measured values. If $2.0 \mathrm{mmol}$ were subtracted from all Hemocue values this rose to $81 \%$ and $68 \%$ and a likelihood ratio of 2.5.

Conclusion-Although more accurate than Reflolux II for the measurement of blood glucose in mothers, HemoCue overreads glucose concentrations in neonates and is therefore potentially dangerous as a screening method for neonatal hypoglycaemia. Reflolux II is useful as a screening method for high risk infants (low birthweight, post-term) and could achieve a post-test probability of detecting hypoglycaemia in a high risk setting like Nepal of $50-60 \%$.

(Arch Dis Child 1996;75:F122-F125)

Keywords: hypoglycaemia, blood glucose, Reflolux II, HemoCue, Nepal.

Dr Anthony de L Costello, Centre for International Child Health, Institute of Child Health, Institute of London WCIN $1 \mathrm{EH}$.

Accepted 6 June 1996

Neonatal hypoglycaemia is a common and neglected problem in many parts of the devel- oping world. An earlier study in the main government maternity hospital in Kathmandu, Nepal, showed that $38 \%$ of uncomplicated term infants experienced mild (blood glucose $<2.6 \mathrm{mmol} / \mathrm{l}$ ) and $8 \%$ moderate/severe (< $2.0 \mathrm{mmol} / \mathrm{l}$ ) hypoglycaemia during the first 48 hours. Infants requiring special care are even more likely to be at risk of hypoglycaemia as a result of prematurity, being small for gestational age, or because of asphyxia or infection. ${ }^{2}$

In most hospitals in the developing world blood glucose is not screened for at the cotside, and often laboratory facilities for venous glucose analysis are unavailable. A lack of resources and limited awareness of the problem compound this. Two cotside methods for blood glucose, which are potentially practical and low cost, are the Reflolux II BM stix and the HemoCue cuvette. However, doubts have been cast on the validity and reliability of both methods at low blood sugar concentrations, when haematocrit concentrations are high, ${ }^{3}$ and in a field situation. ${ }^{4}$ Few studies have used appropriate statistical techniques in method comparison studies: analysis using difference plots and appropriate limits of agreement are preferred to correlation and linear regression. ${ }^{56}$

Our study aimed to compare these two cotside methods of blood glucose measurement against a standard laboratory method, and to estimate their reliability for the detection of neonatal hypoglycaemia in the setting of a maternity hospital in a developing country where hypoglycaemia is known to be common.

\section{Methods}

The study was conducted at Prasuti Griha, a large government funded maternity hospital in Kathmandu, Nepal. Nepal is a low income country with an average income of $\$ 180$ per capita and poor health indicators, including high infant (123/1000 livebirths), and under 5 (189/1000) mortality rates, low female literacy (13\%), and only $10 \%$ of births attended by a trained attendant. ${ }^{5}$

The hospital, the largest maternity unit in the country, provides 250 beds and outpatient services for over 80000 attendances each year. Over 14000 patients are delivered annually with about 1800 admissions to the Special Care Baby Unit.

Earlier studies have shown that neonatal hypoglycaemia is common, ${ }^{1}$ but lack of staff and equipment mean that only high risk infants can be screened for hypoglycaemia at the 
Table 1 Blood glucose (mean, $S D$, and range) concentrations measured in mothers $(n=75)$ and newborn infants ( $n=94)$, and numbers (\%) of hypoglycaemic newborns, using two cutoff definitions ( $<2.6$ and $<2.0 \mathrm{mmol} / \mathrm{l}$ ), using three different methods of measurement for blood glucose

\begin{tabular}{|c|c|c|c|c|}
\hline \multirow[b]{2}{*}{ Method } & $\begin{array}{l}\text { Mothers }(n=75) \\
\text { blood glucose }\end{array}$ & $\begin{array}{l}\text { Infants' }(n=94) \\
\text { blood glucose }\end{array}$ & \multirow{2}{*}{$\begin{array}{l}\text { No of infants (\%) } \\
\text { with blood glucose } \\
<2.6 \mathrm{mmol} / \mathrm{l}\end{array}$} & \multirow{2}{*}{$\begin{array}{l}\text { No of infants (\%) } \\
\text { with blood glucose } \\
<2.0 \text { mmolll }\end{array}$} \\
\hline & \multicolumn{2}{|c|}{ Mean, $(S D)$, median and range } & & \\
\hline Laboratory GOM & $\begin{array}{l}5.3(1.2) 5.2 \\
3.0-8.3\end{array}$ & $\begin{array}{l}2.5(1.1) 2.4 \\
0.4-7.5\end{array}$ & $58(62)$ & 31 (33) \\
\hline Reflolux II & $\begin{array}{l}3.6(1.2) 3.6 \\
1.2-8.4\end{array}$ & $\begin{array}{l}2.1(0.9) 1.8 \\
1.1-7.1\end{array}$ & $72(77)$ & $49(53)$ \\
\hline HemoCue & $\begin{array}{l}5.6(1.0) 5.6 \\
2.6-8.7\end{array}$ & $\begin{array}{l}4.2(1.2) 4.1 \\
2.1-10.4\end{array}$ & $3(3)$ & $0(0)$ \\
\hline
\end{tabular}

Table 2 Sensitivity, specificity (and 95\% confidence intervals), and likelihood ratios for Reflolux II and HemoCue for detection of neonatal hypoglycaemia $(<2.0 \mathrm{mmolll}$ measured using laboratory GOM)

\begin{tabular}{llll}
\hline Cotside method & Sensitivity & Specificity & Likelihood ratio \\
\hline Reflolux II & $83 \%(65-94 \%)$ & $62 \%(49-73 \%)$ & 2.2 \\
HemoCue & $0 \%(0-6 \%)$ & $100 \%(94-100 \%)$ & \\
HemoCue: corrected by subtracting & & & \\
(a) $1.0 \mathrm{mmol}$ & $26 \%(12-44 \%)$ & $92 \%(83-98 \%)$ & 3.3 \\
(b) $1.5 \mathrm{mmol}$ & $58 \%(39-75 \%)$ & $86 \%(75-95 \%)$ & 4.1 \\
(c) $2.0 \mathrm{mmol}$ & $81 \%(63-93 \%)$ & $68 \%(55-79 \%)$ & 2.5 \\
\hline
\end{tabular}

cotside, and there is no on-site facility for blood glucose measurement in the laboratory. Although breastfeeding is the norm in the hospital, many mothers discard colostrum and there is often a delay in starting breastfeeding until 24 hours of age or later.

Ethical approval for the study was given by the Nepal Health Research Council and the MIRA project executive committee.

Ninety four infants were enrolled consecutively from the general wards and Special Care Baby Unit. Inclusion criteria were any infant in whom screening for blood glucose was considered to be clinically valuable-pre- or postterm, low birthweight, hypothermia. Mothers were enrolled after the study had been explained to them and their verbal permission sought. Seventy five mothers agreed to give a blood sample.

Clinical details of the study infants and their mothers were recorded. Venous blood (about $0.5 \mathrm{ml}$ ) was taken from the infants and blood glucose measured immediately at the cotside using both BM 144 stix with the portable Reflolux II meter, and a HemoCue $B$ glucose analyser and cuvettes, batch No UC 075 . (The cuvettes had been transported to Nepal on dry ice and stored in the cold.) The HemoCue is a portable photometric system into which whole blood is introduced by capillary action. After lysis of the cells within the cuvette whole blood glucose concentrations are measured using a coupled glucose dehydrogenase reaction performed in a disposable microcuvette. Technical details have been described elsewhere. ${ }^{7}$ Blood was stored for further analysis in the laboratory. A similar procedure was repeated (when possible) on the infant's mother.

Blood glucose was measured in the laboratory using the Roche Ultimate glucose oxidase method programmed to run on the Roche Cobas Fara analyser, using the manufacturer's protocol. Blood samples were stabilised as follows: $400 \mu$ l of blood was mixed with an equal volume of freshly prepared $6 \%$ perchloracetic acid at the cotside. Samples were immediately stored in a thermos flask containing ice, and then spun at $3000 \mathrm{rpm}$ for 5 minutes within 30 minutes of collection. Supernatant fluids were stored in plastic tubes, labelled, and placed in a $-20^{\circ} \mathrm{C}$ deep freeze. They were subsequently transferred in liquid nitrogen to the United Kingdom for analysis.

As this was a field study the cotside screening results were based on single values for each individual to replicate usual clinical practice. The laboratory standard values were calculated from the mean of duplicate analyses.

Comparisons of the results obtained by each method for both maternal and infant glucose concentrations were made using Bland-Altman difference plots $^{6}$ for the respective cotside method vs laboratory analysis. Correlations between difference and average values indicated whether the difference changed with the magnitude of the measurement.

The sensitivity, specificity, and likelihood ratio for the detection of neonatal hypoglycaemia (defined as $<2.0 \mathrm{mmol} / \mathrm{l}$ measured using the laboratory GOM) was calculated for the two cotside methods. Ninety five per cent confidence intervals were derived from the binomial distribution.

The likelihood ratio for a test result compares the likelihood of that result in patients with disease (in this paper disease is hypoglycaemia $<2.0 \mathrm{mmol} / \mathrm{l}$ ) with the likelihood of that result in patients without disease. Using clinical estimates of the pre-test probability of neonatal hypoglycaemia in this population, the likelihood ratio was applied to a nomogram for Bayes theorem ${ }^{89}$ to estimate the post-test probability of detecting hypoglycaemia.

\section{Results}

Ninety four infants were studied-42 male (45\%) and 52 female (55\%). Their mean birthweight was $2.5 \mathrm{~kg}$ (range 1.3-3.5); 85 were term infants and nine pre-term. The BM stix value on one infant was not recorded. Seventy five mothers agreed to be bled; their mean age was 21 years (range 15-32).

Table 1 shows the mean, standard deviation, and range for blood glucose concentrations measured by each method in the mothers and infants, and the numbers (and \%) of infants with hypoglycaemia defined at two cutoff levels: less than 2.6, and less than 2.0 $\mathrm{mmol} / \mathrm{litre}$. Because this was a selected population of neonates considered to be at clinical risk of hypoglycaemia, the prevalence of moderate/ severe hypoglycaemia (33\%) was considerably higher than that found previously in uncomplicated infants.

The sensitivity, specificity, and likelihood ratios for Reflolux II and HemoCue for the detection of neonatal hypoglycaemia $(<2.0$ $\mathrm{mmol} / \mathrm{l}$ measured using the laboratory GOM) are shown in table 2 .

Figures 1 and 2 show Bland-Altman plots with $95 \%$ limits of agreement (broken lines) and regression line of difference on average for neonatal and maternal blood glucose, respectively. For the Reflolux II data on neonates the correlation between difference and average is 
-0.245 (95\% CI -0.427 to $-0.04, \mathrm{P}<0.02)$, suggesting that the difference increases negatively with the magnitude of blood glucose, although the relation is weak. For the HemoCue data, correlation between difference and average is $0.2(95 \% \mathrm{CI}-0.01$ to 0.39 , $P=0.05$ ), suggesting that the difference increases positively with the magnitude of blood glucose, although the relation is again weak.

For the Reflolux II data on maternal blood there was no correlation between difference and average. For the HemoCue data correlation between difference and average is -0.26 ( $95 \%$ CI -0.46 to $-0.03, P=0.03$ ), suggesting that the difference increases negatively with the magnitude of blood glucose, although the relation is weak.

\section{Discussion}

In this study Reflolux II was the best cotside screening method for detecting cases of hypoglycaemia, although it produced both false positive and false negative results (sensitivity $83 \%$, specificity $62 \%$, likelihood ratio 2.19). Reflolux II tended to underestimate blood glucose, although this did not happen more at lower glucose concentrations.

How can the clinician interpret this information to improve clinical practice, especially in a setting where hypoglycaemia is common and laboratory tests unavailable? We have shown previously that $8-11 \%$ of newborns without complications in the maternity hospital in Kathmandu have moderate or severe hypoglycaemia ( $<2.0 \mathrm{mmol} / \mathrm{l}$ ) during the first 48 hours (unpublished observations) ${ }^{1}$. Low birthweight infants have roughly double the odds of hypoglycaemia as do post-term infants. There
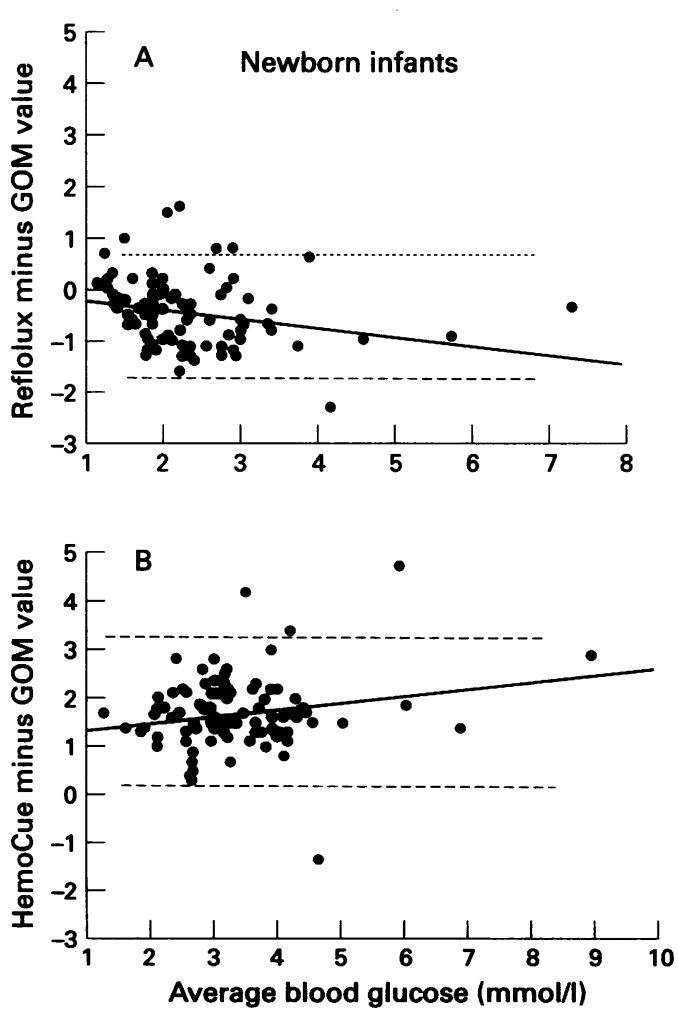

Figure 1 Bland-Alcman difference plots for neonatal blood glucose, with 95\% limits of agreement (broken lines) and regression line of difference on average. is, therefore, a pre-test clinical probability of about $20 \%$ for hypoglycaemia among low birthweight infants in this setting, and perhaps $30-40 \%$ for higher risk low birthweight, post-term infants. These estimates fit with the current results which showed a $30 \%$ prevalence of hypoglycaemia among a selected group of high risk infants considered to need a blood glucose estimation on clinical grounds alone. Using the nomogram adapted from Fagan, ${ }^{89}$ based on pre-test probability and the likelihood ratio of the diagnostic test, a Reflolux II test would achieve a post-test probability of about $35-40 \%$ for the detection of hypoglycaemia in low birthwieght infants and about $50-60 \%$ for a high risk infant.

But in all settings clinicians should be cautious. Kirkham and Watkins ${ }^{10}$ have shown the range of error of reflectance photometers to be wide and recommend that readings that are even slightly low be checked with laboratory estimations.

Although more accurate than Reflolux II for the measurement of blood glucose in mothers, HemoCue was unreliable and potentially dangerous as a screening tool for the detection of neonatal hypoglycaemia. HemoCue overestimated blood glucose at all concentrations. In this setting HemoCue achieved zero sensitivity for the diagnosis of hypoglycaemia and therefore has no value as a screening test. Indeed it would be dangerous to use HemoCue as it would miss most cases.

Why was HemoCue unreliable in this population and setting? The fact that it worked well in mothers but not their newborns measured at
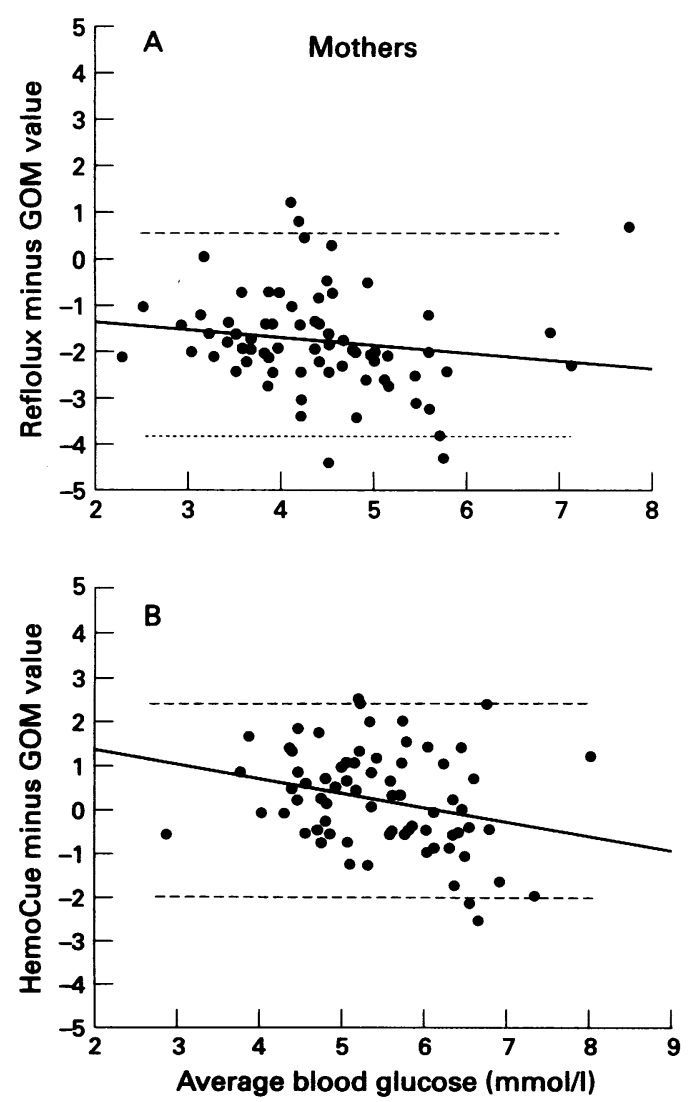

Figure 2 Bland-Alman difference plots for maternal blood glucose, with 95\% limits of agreement (broken lines) and regression line of difference on average. 
the same time would seem to rule out calibration or measurement error, or a fault with the cuvettes arising from transport or storage. Triglyceride concentrations may raise HemoCue readings, ${ }^{7}$ and high haematocrit (common in neonates) may impair the capillary uptake in cuvettes, but neither seems to be adequate explanations. Most evaluations of HemoCue have been conducted using adult blood at higher concentrations of blood glucose, and one of the few studies to have tested the method in newborns examined largely normoglycaemic infants. ${ }^{11}$

Two other studies ${ }^{12}{ }^{13}$ have reported similar findings to this study - that HemoCue results are higher than those produced by a conventional laboratory analyser. Young et al observed that "the absolute concentration measured by HemoCue may be greater than $1.0 \mathrm{mmol} / 1$ higher than YSI (Yellow Springs plasma glucose analyser) concentrations even when approaching hypoglycaemic levels."

The manufacturers of HemoCue have suggested that definitions of hypoglycaemia should be method specific and advise 3.0 $\mathrm{mmol} / \mathrm{l}$ as a cutoff point for intervention. Re-analysing our data using corrected HemoCue results (subtracting $1.0,1.5$ or 2.0 $\mathrm{mmol} / \mathrm{l}$ to the recorded value) gave acceptable sensitivity, specificity, and likelihood ratios (table 2) only after $2.0 \mathrm{mmol}$ had been subtracted from the measured value.
On the basis of these results we cannot support the use of HemoCue for cotside screening of neonatal hypoglycaemia unless cutoff points for intervention are significantly raised.

We are grateful to the British Government Overseas Development Administration for their support.

1 Anderson S, Shakya KN, Shrestha LN, Costello AM de L. Hypoglycaemia: a common problem among uncomplicated newborn infants in Nepal. $\mathcal{F}$ Trop Pediatr 1993; 39:273-7.

2 Cornblath J, Reisner SH. Blood glucose in the neonate and its clinical significance. $N$ Engl $\Im$ Med 1965; 273:378-80.

3 Wiener $K$. The effect of haematocrit on reagent test strips for glucose. Diabet Med 1991;8:172-5.

4 Pickup JC, Crook MA, Tutt P. Blood glucose and glycated haemoglobin measurement in hospital. Which method? Diabet Med 1993;10:402-11.

5 Hollis S. Analysis of method comparison studies. Ann Clin Biochem 1996; 33:1-4.

6 Bland JM, Altman DG. Comparing methods of measurement: why plotting difference against standard method is misleading. Lancet 1995; 346:1085-7.

7 Ashworth L, Gibb I, Alberti KGMM. HemoCue: evaluation of a portable photometric system for determining glucose in whole blood. Clin Chem 1992; 38:1479-82.

8 Fagan TJ. Nomogram for Bayes theorem. $N$ Engl f Med 1975; 293:257.

9 Jaeschke R, Guyatt G, Sackett D. Users' guides to the medical literature. III. How to use an article about a diagnostic cal literature. III. How to use
test. $¥ A M A$ 1994; 271:703-7.

10 Kirkham $\mathrm{P}$, Watkins $\mathrm{A}$. Comparison of two reflectance photometers in the assessment of neonatal hypoglycaemia. Arch Dis Child 1995; 73:F170-F3.

11 Vadasdi E, Jacobs E. HemoCue beta-glucose photometer evaluated for use in a neonatal intensive care unit. Clin Chem 1993; 39:2329-32.

12 Wiener $K$. An assessment of the effect of haematocrit on the HemoCue blood glucose analyser. Ann Clin Biochem 1993; 30:90-3.

13 Young RP, Critchley JAJ, Lau MSW, Lee KKC, Robertshaw AM, Chan TYK, et al. Reliability of glucose measurement using the HemoCue analyser in hypoglycaemia. Ann Clin Biochem 1994; 31:573-5. 